\title{
Extracorporeal Removal of Low Density Lipoproteins Cholesterol and Middle Molecules from Plasma at Metabolic Syndrome, Possibilities of Cellulose Derivates
}

\author{
Khaybullina ZR*, Sadikov RA and Azimova MT \\ Ministry of Health Republic Uzbekistan, Republican Specialized Centre of Surgery named after academician V.Vakhidov, Uzbekistan
}

Submission: August 22, 2017; Published: August 29, 2017

*Corresponding author: Khaybullina ZR, Ministry of health Republic Uzbekistan, Republican Specialized Centre of Surgery named after academician V.Vakhidov, Tashkent, Uzbekistan, Tel: +998 71 239-47-95; Email: zrkhaybullina1@gmail.com

\section{Introduction}

Among US adults aged 18 years or older, the prevalence of metabolic syndrome (MetS) rose by more than $35 \%$ from 1988-1994 to 2007-2012, increasing from $25.3 \%$ to $34.2 \%$ [1] Overweight and obesity - major component of MetS are reaching record-high levels. From 2000 to 2013, the global prevalence of overweight and obesity increased by one-quarter among adults and by nearly half among children; by 2013, more than 2 billion people were overweight, and of these, more than 674 million were obese [2]. In 2010, overweight and obesity were estimated to cause 3.4 million deaths worldwide [3], a number that is likely to increase in line with rising overweight and obesity rates; the annual health care costs attributable to obesity and overweight are more than $\$ 600$ billion [4].

People with the MetS are at increased risk of a cardiovascular disease, such as coronary heart disease or other diseases related to plaque buildups in artery walls (e.g., stroke and peripheral vascular disease) and/or type II diabetes mellitus that characterizes by insulin resistance and impaired insulin secretion [5]. Obesity and MetS are associated with both hyperlipidemya and inflammation, oxidative stress as well as endogenous poisoning due accumulation of middle molecules (interleykin-6 (IL-6), tumor necrosis factor alpha (TNF-a), middle molecular peptides) and low density lipoproteins (LDL) [6]. Increased concentrations of cholesterol of atherogenic apolipo protein B100-containing LDL, high level of C-reactive protein and proinflammatory cytokines, protrombotic state at the patients with MetS escalates the risk of cardiovascular diseases [7]. Both hyperlipidemia correction and loss of weight can restore normoglycemia, decrease of low grade system inflammation and decrease risk of cardiovascular events [8]. The clinical experience demonstrates that administration of high doses of hypolipidemic drugs is not so effective in such patients, as well as fitness can be contraindicated to some group of patients. So, the extracorporeal removal by plasma-sorption or entero-sorption are the only effective to restore normal lipidomic profile and physiologic metabolites concentration [9]. Additional purification from middle and low molecular toxic substances at the patients with MetS can increase effectiveness of treatment. Evidently there is an urgent need to find a method of treating metabolic syndrome and preventing its bad outcomes.

Various types of adsorbents have been designed. There are some sorbents, which are selective to LDL and contained specific ligand or polyclonal antibodies for LDL; another sorbents contained polyacrilates for binding LDL. LDL sorption from both whole blood and plasma can be performed by using different sorption systems: 'Liposorber L" (Kaneka, Japan), "Liposorber D’ (Kaneka, Japan), “LDL Lipopak (POKARD, Russia), “LDL TheraSorb" (Milteney, Germany) systems; sorption from the whole blood can be performed by using DALI (Fresenius, Germany), LDL- 300 (State scientific research institute of very pure biological products, Russia) and LNP 45 (Tosoh, Japan) systems [10]. Cellulose matrix used in "Liposorber L", "Liposorber D”, "LDL-300'. The comparison of different plasma sorbents for removal of LDL indicates that the use of antibodies as ligands ("LDL-300", "LDLLipopac") increases the selectivity, biocompatibility, and stability of the sorption system, but antibodies can cause complications because they are not native for the organism; liposorbents on the base of cellulose derivates are effective, they are cheap and easy available [11]. Sorbents on the charcoal or agarose matrix are less effective then others. Comparative evaluation of different sorption systems shows that the best fractional-dispersed composition is in "LDL-300", the best morphology of beads is in hemosorbents with cellulose beads such as "Liposorber D", "SF LPM", "LDL-300"; the maximal total cholesterol and apoB100- 
binding capacity is found "SFM-LPM", LDL-45 and "LDL-Lipopac" - immunosorbent for plasma perfusion [12]. A reduction in the concentration of Lipoprotein -a (Lp-a) after adsorption for all of the shown sorbents did not exceed 35\% except for high specificity sorbent for Lp-a removal - "Lp-a Lipopack", when it was $80 \%$. The highest specificity of adsorption was demonstrated "LDL45". Despite the simplicity and cost effectiveness of the whole blood perfusion procedure, its effectiveness is insufficient when used in patients with very high LDL levels (more than 300mg/ dl). Plasma-sorption is more effective, than whole blood perfusion at MetS [13]. Using of plasma-sorption can provide purification from TNF-a. TNF-a is one of endogenous fever -caused agents, it can cause hypotension and strong metabolic shifts (increasing intensity of carbohydrates metabolism, exhaustion energy spare, hyperlipidemia) [14]; the mechanism of the direct action of TNF-a is also increasing to expressions of the adhesive molecules on surfaces of endothelium, such as granulocytes, TNF-a mediated the syndromes "holey" capillary and disseminated blood clotting [15]. Nonselective sorption of TNF may be done by using alpha-2 macroglobulin modified by thiol- ethereal loop substance and immobilized on the hard base; human purified albumin adsorbed on the methylacrilate can bind TNF-a and endotoxins too. After thiol-ethereal bond modification alpha -2-macroglobulin became to fast-form and can selectively bind TNF-alpha [16]. Cellulose and its derivates may be potential candidates to TNF-a and another middle molecules elimination [17]. The hydration of cellulose/ silica hybrids (CSH) containing 13, 35, and 46\% (w/w) silica synthesized in situ by a mild sol-gel aqueous process was studied employing sorption isotherms and surface energy measurements: the presence of silica reduces the strength of interaction between monolayer water molecules and the CSH surface as revealed by the net isosteric heat of sorption $(35 \mathrm{~kJ} / \mathrm{mol}$ for cellulosic pulp and $26 \mathrm{~kJ} / \mathrm{mol}$ for $\mathrm{CSH}$ with $35 \%$ silica); silica confers a higher surface energy to CSH contributing to its polar component and surface wet ability (contact angle with water) when compared to cellulosic pulp [18].

The second way of using cellulose derivates for treating MetS is using of water-soluble cellulose derivatives as food ingredient supplement for slowing fat absorption in a high- fat diet. Manufacture of a medicament, pharmaceutical composition, food, food ingredient or supplement, or nutraceutical ingredient or supplement for reducing plasma lipids and cholesterol can influence the level of expression or the concentration of C-reactive protein, plasminogen activator inhibitor-1 (PAI-1), adiponectin, perosisome proliferator-activated receptors alpha (PPAR-alpha), hepatic lipase in a body tissue of an individual [19].

It has been established that water-soluble high- viscosity grades cellulose ether compositions for the reduction of serum lipid levels, particularly total serum cholesterol, serum triglycerides, and LDL levels and/or attenuation of the postprandial rise of blood glucose levels in animals (US Patent No. 5,576,306) ; use of watersoluble cellulose ethers, such as hydroxypropylmethyl cellulose (HPMC) cause reducing the cholesterol level in mammalian blood (U.S. Patent No. 5,585,366); the use of water-soluble, nonnutritive, indigestible, non-starch, viscous polysaccharide, such as water-soluble cellulose ethers cause reducing the percentage of body fat and/or the leptin in the bloodstream of the mammal (U.S. Patent No. 6,899,892); the use of HPMC having a viscosity of 50 to $4,000 \mathrm{cps}$, measured as a 2 weight percent aqueous solution caused reducing total plasma cholesterol levels in a human (U.S. Patent No. 5,721,221). Replacing cellulose in high fat diet with HPMC significantly decreases the incidence of insulin resistance; significantly reduced the glucose infusion rate, fasting plasma insulin, plasma lipids, overall fat distribution in non-adipose tissues, and the cell size of adipose tissues [20].

The use of water-soluble cellulose derivative as dietary fiber for slowing fat absorption in a high- fat diet and its potential reduction in the development of insulin resistance, a precursor to Type II diabetes, for preventing or treating one or more of the symptoms of MetS: hypertension, proinflammatory or inflammation state and prothrombotic state in an individual [21]. Thus, preferred cellulose derivatives are water-soluble cellulose esters and cellulose ethers, which can be used as enterosorbtion and plasma absorbers.

\section{References}

1. Moore JX, Chaudhary N, Akinyemiju T (2017) Metabolic syndrome prevalence by race/ethnicity and sex in the united states, national health and nutrition examination survey, 1988-2012. Prev Chronic Dis 14: E24.

2. Ng M, Fleming T, Robinson M, Thomson B, Graetz N, et al. (2014) Global, regional, and national prevalence of overweight and obesity in children and adults during 1980-2013: a systematic analysis for the Global Burden of Disease Study 2013. Lancet 384(9945): 766-781.

3. Lim SS, Vos T, Flaxman AD, Danaei G, Shibuya K, et al. (2013) A comparative risk assessment of burden of disease and injury attributable to 67 risk factors and risk factor clusters in 21 regions, 1990-2010: a systematic analysis for the Global Burden of Disease Study 2010. Lancet 380(9859): 2224-2260.

4. (2013) Sugar consumption at a crossroads. Credit Suisse.

5. Genel S, Emanuella F, Lucia SM (2015) Metabolic Syndrome -a bomb with delayed reaction. J Bioequiv Availab 7: 155-157.

6. ZR Khaybullina (2017) Inflammation and oxidative stress - critical role for metabolic syndrome (mini-review). J Vasc Med Surg 5: 302.

7. Abu-Farha M, Behbehani K, Elkum N (2014) Comprehensive analysis of circulating adipokines and hsCRP association with cardiovascular disease risk factors and metabolic syndrome in Arabs. Cardiovasc Diabetol 9(13): 76.

8. Nazirov FG, Khaybullina ZR, Khashimov ShKh, Makhmudov UM (2016) Laparoscopic Sleeve Gasterectomy reduces inflammation and cardio metabolic risk in obese patients. Cardiovascular pharmacology: open access 5: 200 .

9. Afanaseva OI, Altynova EV, Boldyrev AG, Sokolov AA (2006) Comparative analysis of efficiency and specificity of various sorbents for apheresis of low-density lipoproteins. Bull Exp Biol Med 142(5): 587-590.

10. Morozov AS, Bessonov IV, Nuzhdina AV, Pisarev VM (2016) Sorbents for extracorporeal removal of toxic substances and molecules with adverse biological activity. GENERAL resuscitator 12(6): 82-107. 
11. Dorskaya EV, Cherkasova TA, Leykin Yu A (2007) Synthesis and investigations of sorbents for low density lipoproteins extraction from biological fluids of organism. Successes in chemistries of chemical technology 10(78): 65-69.

12. Afanaseva OI, Altynova EV, Kuznetsov YuV, Boldyrev AG, Sokolov AA, et al. (2006) Imnmuno haemo sorbents for whole blood perfusion (synthesis and characteristics). Efferent Therapy 12(4): 15-20.

13. Altynova EV, Afanaseva OI, Boldyrev AG, Potokin IL, Sokolov AA (2006) Adsorbents for LDL apheresis for blood perfusions (in vitro comparison). Efferent Therapy 12(4): 3-14.

14. Subhapria S, Tomi L, Padmanaban VC (2013) Atherosclerosis: critica role of oxidation and inflammation. Int J Pharm Pharm Sci 5(1 4): 5-8.

15. Khaybullina Z, Mirjamol Z, Nodir S, Saidariphon M, Saodat A (2017) Oxidative stress-indused effects on proinflammatory cytokines and vascular endothelial growth factor after interventional treatment of coronary heart disease. J Clin Exp Cardiolog 8(Suppl): 89.

16. Kivva VN, Anuphrienko VF, Redkina LV (2001) Methods of apheresis Patent of Russia Federation № 2162344. A61M1/38.
17. Zhang J (2001) Jun Advanced functional materials based on cellulose Acta Polymerica Sinica (Journal of Polymer Science) 10(12): 13761398.

18. (2005) Hydroxypropylmethylcellulose (HPMC) may prevent insulin resistance in hamsters fed high saturated fat diets through regulating metabolic genes. ACS (American Chemical Society) meeting, California, USA.

19. Lynch SK, Conklin J, Yokoyama W, Hong YJ, Turowski M (2008) Uses of water-soluble cellulose derivatives for preventing or treating metabolic syndrome. US patent.

20. Espino-Pérez E, Bras J, Almeida G, Relkin P, Belgacem N, et al. (2016) Cellulose nano crystal surface functionalization for the controlled sorption of water and organic vapours. Cellulose 23(5): 2955-2970.

21. Portugal I, Dias VM, Duarte RF, Evtuguin DV (2010) Hydration of cellulose/silica hybrids assessed by sorption isotherms. J Phys Chem B 114(11): 4047-4055.

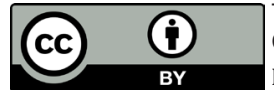

This work is licensed under Creative Commons Attribution 4.0 License

DOI: 10.19080/JOCCT.2017.07.555719 